\title{
Gestão de projetos internacionais: um estudo bibliométrico
}

\section{Management of international projects: a bibliometric study}

\author{
Hugo Martinelli Watanuki ${ }^{1}$ \\ Jeniffer de Nadae ${ }^{1}$ \\ Marly Monteiro de Carvalho' \\ Renato de Oliveira Moraes ${ }^{1}$
}

\begin{abstract}
Resumo: A economia global, apoiada no avanço tecnológico, reformas políticas e interdependência econômica, proporcionou um ambiente de negócios que difere radicalmente dos cenários do passado. Esse novo contexto conduziu as empresas ao desenvolvimento e execução de projetos que ultrapassam suas fronteiras nacionais, tanto em termos de escopo, como em relação à composição das equipes de projeto. Todavia, os projetos internacionais geralmente implicam riscos e incertezas maiores que os projetos tradicionais, tornando a competência em gestão de projetos internacionais um elemento estratégico para as organizações da atualidade. O objetivo deste trabalho é realizar uma análise da literatura sobre o tema de gerenciamento de projetos internacionais, buscando identificar os principais desafios e características desta gestão. A abordagem metodológica utilizada é a de revisão sistemática da literatura, tendo como base a teoria bibliométrica e a análise de redes sociais. A base de dados escolhida para a seleção dos artigos que compõem a amostra foi a ISI Web of Knowledge (Web of Science). As análises conduzidas sugerem que grande parte da literatura disponível envolvendo o tema de gerenciamento de projetos internacionais apoia-se em pesquisas cujas bases teóricas remetem a investigações de diferenças culturais e comportamentais entre indivíduos. Os resultados também sugerem que um dos principais desafios à gestão de projetos internacionais reside na integração adequada do projeto em si e suas equipes dispersas, processo que é dificultado por barreiras comunicativas, de compartilhamento de conhecimento e de tomada de decisão inerentes a esse contexto.
\end{abstract}

Palavras-chave: Projetos internacionais. Gestão de projetos. Estudo bibliométrico.

\begin{abstract}
The global economy, supported by technological progress, political changes and economic interdependency, has shaped a business environment that differs radically from the past. This new context has conducted organizations to develop and execute projects beyond national boundaries, both in terms of project scope and composition of project teams. However, international projects usually imply greater risks and uncertainty, making competence in the management of international projects a strategic element to organizations these days. The aim of this paper is to analyze the literature related to the management of international projects, trying to identify the main challenges and characteristics of this management activity. The methodological approach is based on systematic literature review, supported by bibliometric techniques and social network analysis. The database chosen for the selection of sample articles was the ISI Web of Knowledge (web of Science). Analyses suggest that a major portion of the literature related to the management of international projects has its theoretical foundations on investigations of cultural and behavioral differences between individuals. Results also suggest that one of the main challenges to the management of international projects resides on the effective integration of the project itself and its dispersed teams, a process that tends to be hampered by communicative, knowledge sharing, and decision making barriers inherent to this context.
\end{abstract}

Keywords: International projects. Project management. Bibliometric study.

\footnotetext{
${ }^{1}$ Departamento de Engenharia de Produção, Escola Politécnica - POLI, Universidade de São Paulo - USP, CEP 05508-900, São Paulo, SP, Brasil, e-mail: hwatanuki@usp.br; nadae.jeniffer@usp.br; marlymc@usp.br; remo@usp.br
} 


\section{Introdução}

O processo de internacionalização das organizações de um país é um dos indicadores do seu grau de desenvolvimento e possibilita às empresas tornarem-se mais competitivas em nível internacional a fim de manterem seus mercados internos e expandirem seus negócios no mercado internacional (FLEURY; FLEURY, 2011). Associado à adoção, por parte das organizações, de Tecnologias da Informação (TI) para mediação da comunicação, esse processo de internacionalização conduziu as empresas ao desenvolvimento e execução de projetos além de suas fronteiras nacionais e cujas equipes de projeto são constituídas por membros dispersos por diferentes países. Esse tipo especial de projeto denomina-se projeto internacional ou transnacional (BOUTELLIER et al., 1998). Os projetos internacionais são muito atraentes para as organizações que buscam expandir seu portfólio de negócios e a rede de colaboração entre os parceiros internacionais e suas unidades de negócio (STEFFEY; ANANTATMULA, 2011). Esse cenário tem proporcionado novos ambientes de trabalho, tais como ambientes de trabalho distribuídos ou virtuais, que diferem das estruturas tradicionais e convencionais $\mathrm{e}$, muitas vezes, adicionam desafios para a área de gerenciamento de projetos.

O gerenciamento de projetos, como um campo multidisciplinar, sempre esteve alinhado com mudanças nas práticas gerenciais e de processos de negócios. Com a globalização da indústria atual, entretanto, a implementação bem-sucedida de projetos depende não somente do uso efetivo de ferramentas e técnicas gerenciais em um ambiente organizacional em particular, mas sim no uso efetivo de tais técnicas em diferentes regiões geográficas, as quais, geralmente, incorporam grandes diferenças em suas respectivas culturas organizacionais (KRUGLIANSKAS; THAMHAIN, 2000).

Diante desse contexto, o objetivo principal deste trabalho é analisar a literatura sobre o tema de gestão de projetos internacionais, buscando identificar os desafios e características do gerenciamento desse tipo de projeto. A abordagem metodológica utilizada é de revisão sistemática da literatura, tendo como base a teoria bibliométrica e a análise de redes sociais. Tal processo busca identificar os principais temas tratados na área, tendências e lacunas, bem como os principais autores e obras.

Este artigo está estruturado em cinco seções. A descrição do método de seleção da amostra de artigos e as técnicas de análise são apresentadas na seção 2. Na seção 3, são apresentados os resultados encontrados e, nas seções 4 e 5 , as discussões e conclusões da pesquisa, respectivamente.

\section{Métodos de pesquisa}

O estudo bibliométrico é uma ferramenta de análise quantitativa da literatura e foi introduzida como uma técnica de análise por Pritchard em 1969 (SUN; WANG; HO, 2012). Segundo Gumpenberger e Gorraiz (2012), a bibliometria é uma disciplina das ciências da biblioteca e da informação, sendo desenvolvida como uma ferramenta para medir e monitorar a produção científica. A análise bibliométrica tem amplas aplicações em diversas áreas com o intuito de aumentar o desempenho de pesquisas ou avaliar suas tendências, investigando as características das publicações, tais como: autoria, fontes de pesquisa, temas, origens geográficas, citações e cocitações (SMALL, 2003).

Para a condução desse estudo bibliométrico, a base de dados escolhida para a seleção dos artigos que compõem a amostra foi a ISI Web of Knowledge (Web of Science). A base ISI foi escolhida para composição da amostra inicial pelo fato de ser amplamente suportada por ferramentas de software que permitem recuperar maior variedade de metadados de interesse da pesquisa, tais como: abstract, cited references, times cited, authors, institutions e countries - viabilizando, portanto, as análises desenvolvidas neste estudo. Os processos de busca da base ISI também localizam artigos publicados em outras bases, mas cujo abstract está também indexado na ISI, particularmente os periódicos indexados, cujo fator de impacto é apurado pelo Journal Citation Report (JCR). Dessa maneira, a partir dessa base de dados, a amostra pôde ser expandida, pelo método de bola de neve, para outras bases e outros tipos de publicação que não somente artigos, mas também livros e anais de congresso, citados na amostra inicial. Por outro lado, restrições do ponto de vista do processo metodológico e dos softwares de bibliometria utilizados também convergiram para a escolha da base ISI. A condução da análise de redes sociais a partir dos dados da base ISI em conjunto com outras bases é inviabilizada devido à incompatibilidade entre o formato e tipologia dos metadados exportados dessa base em relação a outras bases como a Scopus, por exemplo.

As palavras-chave utilizadas para a busca na base ISI foram: "International Project"; "Global team"; "International team", "Management", "Virtual team" e "Project Management", utilizando como critério de seleção publicações nas áreas de engenharia (Engineering), economia (Business Economics) e gestão (Operations Research Management Science). Optou-se pela inclusão da palavra-chave "virtual team" na busca por esta ser, muitas vezes, uma temática relevante no contexto de projetos internacionais, trazendo pesquisas relacionadas e, nesse caso, evitando a exclusão indevida de artigos pertinentes ao estudo. No entanto, destaca-se que esses termos não são 
sinônimos. Como definem Sotomonte e Silva (2011, p. 05) em seu estudo bibliográfico sobre equipes virtuais:

Um grupo de pessoas que trabalham colaborativamente de forma síncrona ou assíncrona, podendo ser em diferentes tipos de equipe [...] podem estar em diferentes partes do mundo ou organizações, utilizando um ciberespaço de forma que a tecnologia e os recursos cooperem para que o projeto seja executado e controlado a distância.

Desta forma, uma equipe virtual, não necessariamente é um projeto internacional.

Com estes critérios, 121 artigos foram encontrados. Cada artigo da amostra foi registrado individualmente utilizando-se o software Mendeley e os metadados dessa amostra inicial, tais como título, resumo, título do periódico, referências, entre outros, foram exportados. O arquivo em Microsoft Access contendo todos os metadados foi gerado pelo software Sitkis (SCHILDT, 2002). Em seguida, a leitura dos artigos foi feita separadamente pelos pesquisadores e apenas os artigos identificados para exclusão por consenso foram retirados da amostra. A exclusão dos artigos pautou-se em dois critérios.

O primeiro critério de descarte consistiu em excluir as publicações que não possuíam relação direta com o tema gerenciamento de projetos. Utilizando esse critério, 26 artigos foram excluídos, pois tratavam de temas especificamente relacionados à gestão de operações, sistemas de apoio à decisão e análises financeiras, nessa ordem. O segundo critério utilizado consistiu na exclusão de publicações que, embora abordassem o tema gerenciamento de projetos, não tratavam especificamente de projetos internacionais. Com a utilização desse critério, 20 artigos foram excluídos, os quais em sua absoluta maioria tratavam de temas relacionados apenas à importância das práticas de gerenciamento de projetos de forma generalizada. Depois da criteriosa análise, 75 publicações, aproximadamente $62 \%$ da amostra inicial, compõem a amostra deste estudo bibliométrico. Com base nos metadados dessas publicações e com o auxílio do software Sitkis (SCHILDT, 2002) foi possível, pelo método de bola de neve, ter acesso às informações das 2.857 referências utilizadas pelos artigos da amostra.
Uma vez definida a amostra, os artigos foram tratados em primeiro lugar com estatística descritiva, apresentando a distribuição por ano, autor, periódico, país e número de citações. Em seguida, foi feita a análise de citação e cocitação dos artigos da amostra e de suas referências, bem como a análise de coocorrência de palavras-chave dos artigos da amostra. Para condução dessas análises, foram elaboradas redes sociais e calculados os indicadores de centralidade e intermediação das respectivas redes obtidas, conforme fórmulas propostas em Wasserman e Faust (1994) e apresentadas no Quadro 1. A condução destas análises apoiou-se na utilização dos softwares Sitkis (SCHILDT, 2002) e Ucinet (BORGATTI; EVERETT, M.; FREEMAN, 2002).

\section{Apresentação dos resultados}

\subsection{Análise das publicações}

Uma primeira análise descritiva das publicações procurou identificar tendências de crescimento ou decréscimo no interesse de desenvolvimento de estudos na área, classificando os artigos da amostra de acordo com o ano de publicação (Figura 1). Observa-se que a primeira publicação relacionada com o tema data do ano de 1993, sendo que nos anos seguintes o volume de publicações apresenta um caráter cíclico com picos de volume de publicações nos anos 2000, 2006 e 2010, intercalados por períodos com menor volume de publicações.

Analisando o tema dos artigos publicados especificamente durante esses três anos, observa-se que no ano 2000 predomina a discussão a respeito de projetos de Tecnologia de Informação (TI) e Pesquisa e Desenvolvimento (P\&D) de novas tecnologias em ambiente global. Em 2006 a temática predominante das publicações aborda projetos de engenharia e construção civil desenvolvidos simultaneamente em diversos países. Em 2010 os temas dos artigos apresentam-se voltados à gestão de projetos internacionais de forma mais ampla, destacando pontos como os desafios associados ao gerenciamento de equipes de projeto culturalmente diversas, os aspectos gerenciais a serem considerados em ambientes de projeto globais e estudos sobre a importância dos escritórios de projetos (Project Management Office - PMO).

Quadro 1. Fórmulas para cálculo de centralidade e intermediação. Fonte: Adaptado de Wasserman e Faust (1994).

\begin{tabular}{|c|c|c|}
\hline Centralidade & $C^{\prime} D(n i)=d(n i) /(g-1)$ & $\begin{array}{l}\text { C'D (ni) } \rightarrow \text { centralidade } \\
\mathrm{d}(\text { ni) } \rightarrow \text { número de laços } \\
\mathrm{g} \rightarrow \text { número de atores }\end{array}$ \\
\hline Intermediação & $\mathrm{Pp}(\mathrm{ni})=(\mathrm{Ii} /(\mathrm{g}-1)) / \sum \mathrm{D}(\mathrm{nj}, \mathrm{ni}) / \mathrm{Ii}$ & $\begin{array}{l}\text { Pp }(\text { ni }) \rightarrow \text { intermediação } \\
\mathrm{Ii} \rightarrow \text { número de atores que se relacionam com o ator i } \\
\mathrm{d}(\mathrm{nj}, \text { ni) } \rightarrow \text { número de laços do ator j para o ator i } \\
\mathrm{g} \rightarrow \text { número de atores }\end{array}$ \\
\hline
\end{tabular}


Uma segunda análise descritiva procurou avaliar a dispersão dos trabalhos, a fim de identificar os principais autores, países de origem e periódicos em volume de publicações, conforme indicado nas Figuras 2, 3 e 4.

Com relação à distribuição dos trabalhos por autor (Figura 2), a análise da amostra revelou uma dispersão considerável. Os autores com maior número de trabalhos são representados por um grupo constituído de 11 autores, cada um possuindo duas publicações na amostra.

A estratificação das publicações por país de origem demonstra um predomínio acentuado de publicações originárias dos Estados Unidos, seguido pela Finlândia e China (Figura 3). As 26 publicações originárias dos Estados Unidos apresentam uma distribuição

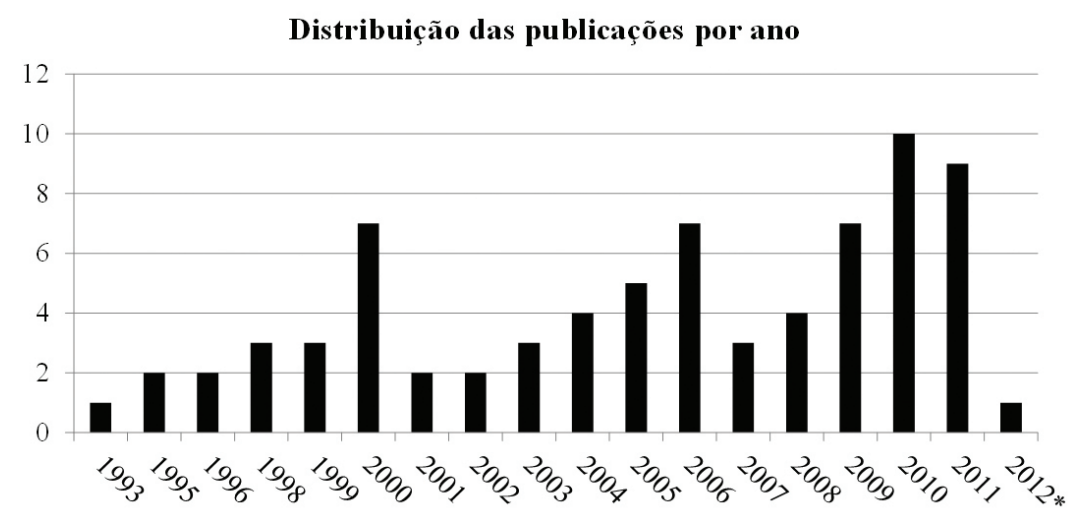

Figura 1. Evolução das publicações da amostra ao longo do tempo (*até março de 2012).

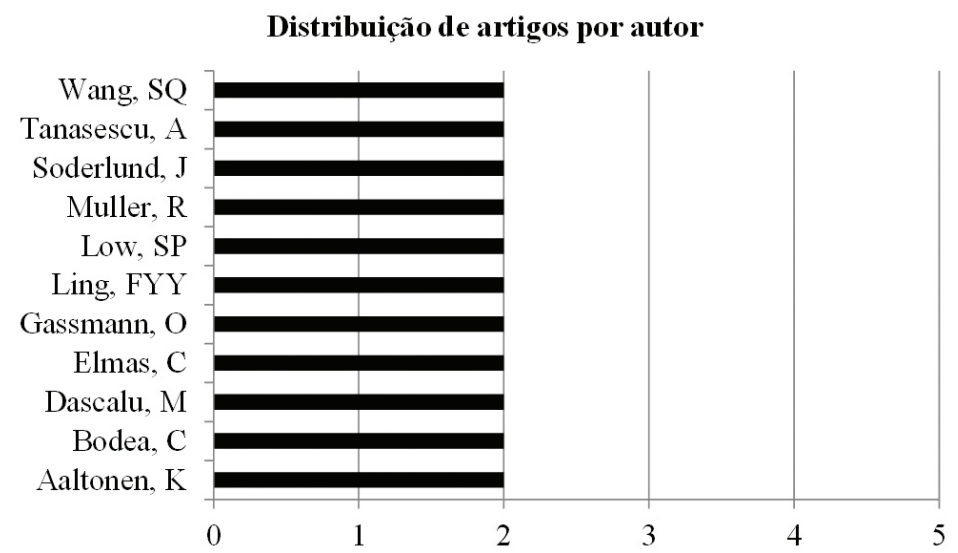

Figura 2. Autores com maior número de publicações da amostra (AALTONEN, 2011; BODEA et al., 2010; LING et al., 2008, 2009; MULLER; TURNER, 2010).

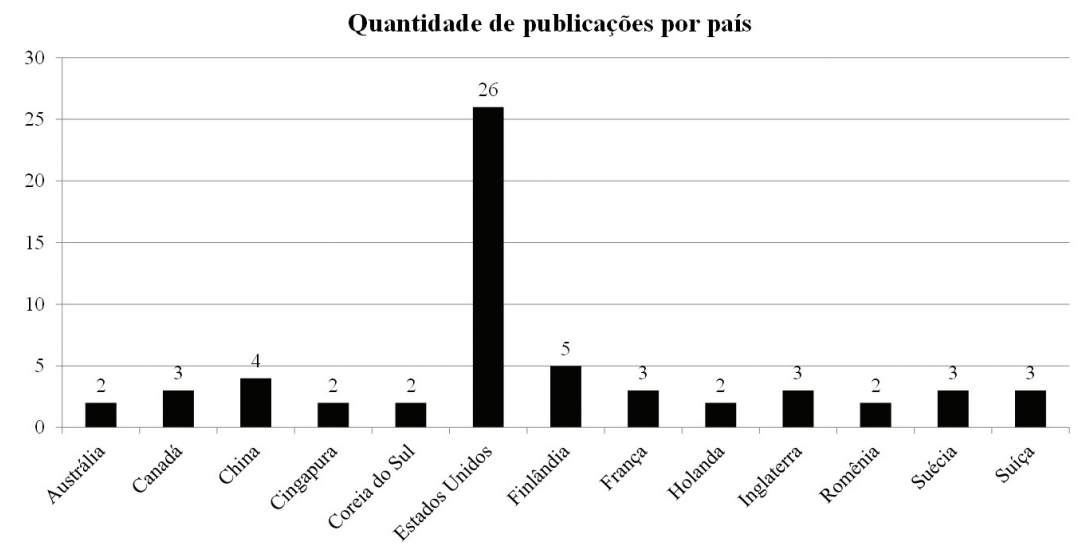

Figura 3. Distribuição das publicações da amostra por país de origem (considerando-se apenas os países com mais de uma publicação na amostra selecionada). 


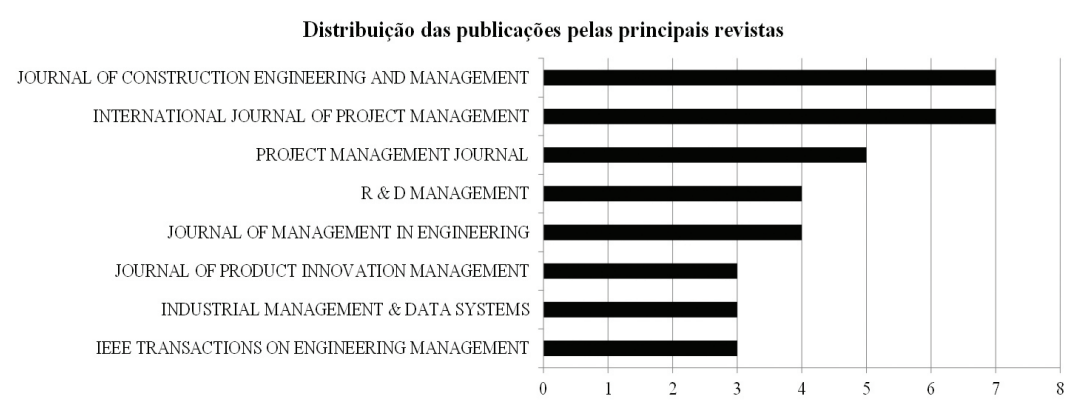

Figura 4. Comparativo da distribuição das publicações da amostra pelos principais periódicos.

uniforme ao longo dos anos e abordam as mais diferentes facetas da gestão de projetos internacionais, englobando discussões a respeito de ambientes distribuídos de $\mathrm{P} \& \mathrm{D}$, projetos internacionais de TI e projetos de construção civil internacionais. As publicações originárias da Finlândia, por sua vez, estão concentradas nos anos de 2010 e 2011 e versam, principalmente, sobre a complexidade dos projetos internacionais e análise de particularidades da cultura finlandesa no contexto de projetos internacionais. As publicações originárias da China estão concentradas principalmente nos anos de 2006 e 2008 e focam projetos internacionais da construção civil e de TI, bem como desafios particulares da cultura chinesa para a condução de projetos internacionais.

Já com relação à distribuição dos artigos da amostra por revista de publicação, observa-se na Figura 4 que, embora não haja um periódico com destaque significativo em volume de publicações, os três periódicos que apresentam maior número de publicações sobre o tema são o Journal of Construction Engineering and Management, o International Journal of Project Management e o Project Management Journal.

Os artigos com os maiores números de citações da amostra são apresentados no Quadro 2. Dos cinco trabalhos mais citados, quatro discutem a utilização de equipes virtuais ou globais em projetos de desenvolvimento de produtos ou projetos de P\&D de novas tecnologias.

Objetivando identificar os trabalhos de maior impacto da área, o Quadro 2 também apresenta alguns outros índices a serem considerados, tais como o fator de impacto do periódico e o índice de impacto corrigido (LOPES; CARVALHO, 2012). O Journal Citation Reports é um recurso que permite avaliar e comparar os periódicos e sua relevância em uma determinada área por meio do fator de impacto (JOURNAL..., 2013). Portanto, no Quadro 2, apresenta-se o fator de impacto para o grupo de publicações mais citado. O Quadro 2 também apresenta o índice de impacto corrigido das publicações, proposto por Lopes e Carvalho (2012) e que considera tanto o impacto do periódico como o número de citações do artigo, conforme Equação 1.

Índice corrigido de citações $=$ número de citações do artigo * (fator de impacto +1$)$

Equação 1 - Cálculo do índice corrigido de citações.

\subsection{Análise das redes sociais}

Depois da análise descritiva das publicações, foi feita uma análise de redes sociais com o intuito de entender as implicações dos padrões de relacionamento dos estudos publicados na área de gestão de projetos internacionais.

Primeiramente, na busca de identificação das bases teóricas sobre as quais a amostra de publicações foi desenvolvida, construiu-se uma rede de relacionamento entre os artigos da amostra e suas referências. O resultado dessa primeira análise está demonstrado na Figura 5. Embora não haja uma concentração clara em torno de referências específicas, pode-se observar que quatro referências foram compartilhadas simultaneamente por três artigos da amostra, revelando certa influência nos trabalhos da área. Essas referências correspondem aos trabalhos de Eisenhardt (1989), Hofstede (1980), Gersick (1988) e Wheelwright e Clark (1992).

A análise de cocitação foi conduzida com o objetivo de identificar os pares de referências mais utilizadas pelos trabalhos da amostra e também auxilia na consolidação da avaliação das bases teóricas das publicações. Os resultados dessa análise evidenciaram agrupamentos relacionados com temáticas diversas: fatores críticos de sucesso (FCS), diferenças culturais entre sociedades, métodos qualitativos de pesquisa, gestão de projetos de grande porte, gestão de organizações temporárias e estudos comportamentais humanos (Figura 6).

Os resultados dos cálculos de centralidade e intermediação dos nós da rede de cocitação são mostrados nos Quadros 3 e 4, respectivamente. Observa-se que o artigo de Eisenhardt (1989) possui o maior grau de centralidade, indicando que essa publicação apresenta o maior número de conexões 
Quadro 2. Publicações mais citadas da amostra.

\begin{tabular}{|c|c|c|c|c|c|}
\hline Autores & Periódico & Ano & $\begin{array}{l}\mathbf{N}^{\circ} \text { de } \\
\text { citações }\end{array}$ & $\begin{array}{c}\text { Índice de } \\
\text { impacto } \\
\text { (JOURNAL..., } \\
\text { 2011) }\end{array}$ & $\begin{array}{l}\text { Índice } \\
\text { corrigido }\end{array}$ \\
\hline $\begin{array}{l}\text { ETHIRAJ, S. K.; KALE, P.; } \\
\text { KRISHNAN, M. S.; SINGH, J. V. }\end{array}$ & Strategic Management Journal & 2005 & 134 & 3,783 & 640,922 \\
\hline $\begin{array}{l}\text { McDONOUGH, E. F.; KAHN, K. } \\
\text { B.; BARCZAK, G. }\end{array}$ & $\begin{array}{l}\text { Journal of Product Innovation } \\
\text { Management }\end{array}$ & 2001 & 116 & 2,109 & 360,644 \\
\hline $\begin{array}{l}\text { BOUTELLIER, R.; GASSMANN, } \\
\text { O.; MACHO, H.; ROUX, M. }\end{array}$ & $R \& D$ Management & 1998 & 64 & 2,507 & 224,448 \\
\hline $\begin{array}{l}\text { LINDKVIST, L.; SÖDERLUND, } \\
\text { J.; TELL, F. }\end{array}$ & Organization Studies & 1998 & 56 & 2,328 & 186,368 \\
\hline $\begin{array}{l}\text { GASSMANN, O.; VON } \\
\text { ZEDTWITZ, M. }\end{array}$ & $R \& D$ Management & 1998 & 50 & 2,507 & 175,350 \\
\hline MONTEALEGRE, R.; KEIL, M. & Mis Quarterly & 2000 & 49 & 4,447 & 266,903 \\
\hline KIRSCH, L. J. & Information Systems Research & 2004 & 46 & 2,146 & 144,716 \\
\hline SAPSED, J.; SALTER, A. & Organization Studies & 2004 & 33 & 2,328 & 109,824 \\
\hline SOUDER, W. E.; JENSSEN, S. A. & $\begin{array}{l}\text { Journal of Product Innovation } \\
\text { Management }\end{array}$ & 1999 & 29 & 2,109 & 90,161 \\
\hline GUNHAN, S.; ARDITI, D. & $\begin{array}{l}\text { Journal of Construction } \\
\text { Engineering and Management }\end{array}$ & 2005 & 26 & 0,818 & 47,628 \\
\hline $\begin{array}{l}\text { YAN, Y. H.; KUPHAL, T.; } \\
\text { BODE, J. }\end{array}$ & $\begin{array}{l}\text { International Journal of } \\
\text { Production Economics }\end{array}$ & 2000 & 23 & 1,760 & 63,48 \\
\hline CHIESA, V. & $\begin{array}{l}\text { Journal of Product Innovation } \\
\text { Management }\end{array}$ & 2000 & 22 & 2,109 & 68,398 \\
\hline $\begin{array}{l}\text { IBBS, C. W.; KWAK, Y. H.; NG, } \\
\text { T.; ODABASI, A. M. }\end{array}$ & $\begin{array}{l}\text { Journal of Construction } \\
\text { Engineering and Management }\end{array}$ & 2003 & 18 & 0,818 & 32,724 \\
\hline SÖDERLUND, J. & $R \& D$ Management & 2002 & 17 & 2,507 & 59,619 \\
\hline JUNG, J. Y.; WANG, Y. H. & Technovation & 2006 & 14 & 3,287 & 60,018 \\
\hline $\begin{array}{l}\text { KRUGLIANSKAS, I.; } \\
\text { THAMHAIN, H. J. }\end{array}$ & $\begin{array}{l}\text { IEEE Transactions on } \\
\text { Engineering Management }\end{array}$ & 2000 & 14 & 0,958 & 27,412 \\
\hline
\end{tabular}

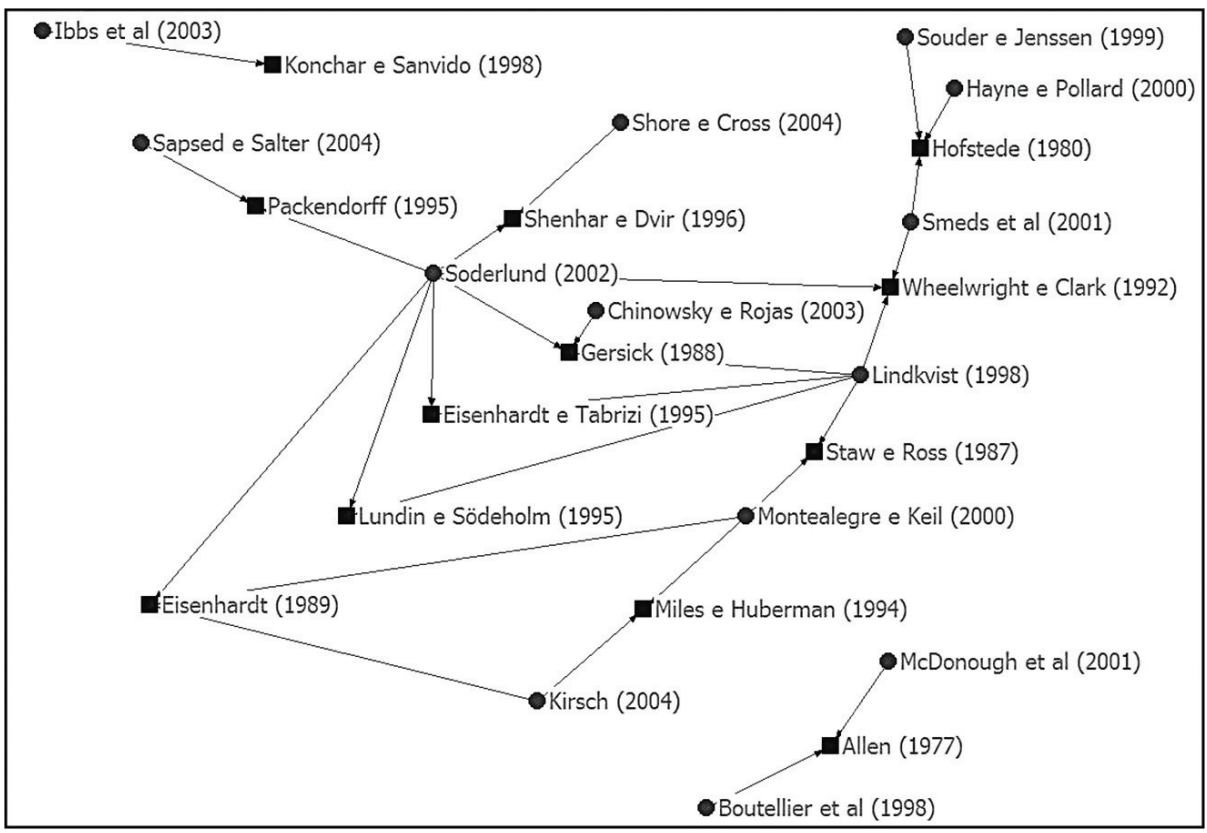

Figura 5. Rede de relacionamento entre os artigos da amostra e suas referências. Nota: Os círculos representam os artigos da amostra inicial e os quadrados, suas referências que foram citadas pelo menos três vezes. 
diretas com outras publicações da rede de cocitação. Já os artigos de Hofstede $(1980,2001)$ apresentaram o maior grau de intermediação dessa mesma rede, indicando que essas publicações exercem grande intermediação entre todos os pares possíveis de publicações da rede.
Como última etapa da análise de redes sociais, estabeleceu-se uma relação de coocorrência das palavras-chave dos artigos da amostra (Figura 7). Nessa análise, a fim de restringir a quantidade de dados e proporcionar uma visão mais nítida dos relacionamentos, o critério de corte consistiu em

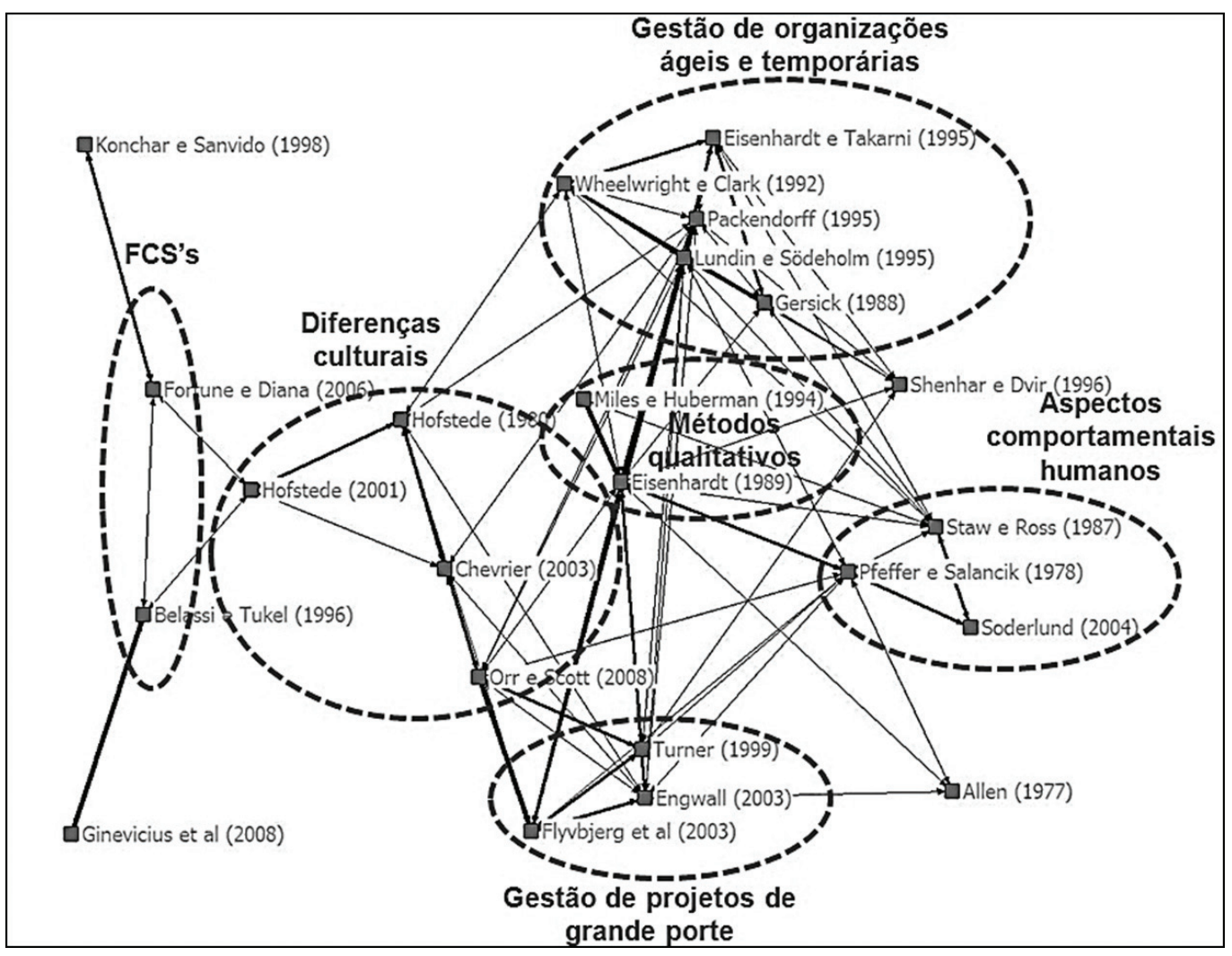

Figura 6. Rede de cocitação. Nota: Os quadrados representam as referências dos artigos da amostra que foram citadas conjuntamente pelo menos três vezes. A espessura das linhas representa a intensidade dos vínculos entre o par de referências.

Quadro 3. Resultados de centralidade para cada publicação da rede de cocitação. Nota: Foram consideradas apenas as quinze publicações com os maiores graus de centralidade.

\begin{tabular}{|l|c|c|}
\hline \multicolumn{1}{|c|}{ Publicação } & Grau de centralidade & $\begin{array}{c}\text { Grau de centralidade } \\
\text { normalizado }\end{array}$ \\
\hline Eisenhardt (1989) & 21,000 & 31,818 \\
\hline Lundin e Södeholm (1995) & 18,000 & 27,273 \\
\hline Flyvbjerg, Bruzelius e Rothengatter (2003) & 15,000 & 22,727 \\
\hline Orr e Scott (2008) & 13,000 & 19,697 \\
\hline Wheelwright e Clark (1992) & 11,000 & 16,667 \\
\hline Engwall (2003) & 11,000 & 16,667 \\
\hline Packendorff (1995) & 11,000 & 16,667 \\
\hline Pfeffer e Salancik (1978) & 11,000 & 16,667 \\
\hline Gersick (1988) & 10,000 & 15,152 \\
\hline Eisenhardt e Tabrizi (1995) & 10,000 & 15,152 \\
\hline Hofstede (1980) & 10,000 & 15,152 \\
\hline Staw e Ross (1987) & 9,000 & 13,636 \\
\hline Turner (1999) & 8,000 & 12,121 \\
\hline Shenhar e Dvir (1996) & 7,000 & 10,606 \\
\hline Chevrier (2003) & 7,000 & 10,606 \\
\hline
\end{tabular}


Quadro 4. Grau de intermediação para cada publicação da rede de cocitação. Nota: Foram consideradas apenas as quinze publicações com os maiores graus de intermediação.

\begin{tabular}{|l|c|c|}
\hline \multicolumn{1}{|c|}{ Publicação } & Grau de intermediação & $\begin{array}{c}\text { Grau de intermediação } \\
\text { normalizado }\end{array}$ \\
\hline Hofstede (2001) & 72,000 & 31,169 \\
\hline Hofstede (1980) & 50,229 & 21,744 \\
\hline Eisenhardt (1989) & 31,300 & 13,550 \\
\hline Chevrier (2003) & 31,087 & 13,458 \\
\hline Packendorff (1995) & 23,456 & 10,154 \\
\hline Belassi e Tukel (1996) & 21,000 & 9,091 \\
\hline Fortune e Diana (2006) & 21,000 & 9,091 \\
\hline Engwall (2003) & 17,884 & 7,742 \\
\hline Wheelwright e Clark (1992) & 17,067 & 7,388 \\
\hline Pfeffer e Salancik (1978) & 16,644 & 7,205 \\
\hline Orr e Scott (2008) & 13,284 & 5,751 \\
\hline Flyvbjerg, Bruzelius e Rothengatter (2003) & 13,284 & 5,751 \\
\hline Staw e Ross (1987) & 11,256 & 4,873 \\
\hline Lundin e Södeholm (1995) & 8,967 & 3,882 \\
\hline Shenhar e Dvir (1996) & 1,200 & 0,519 \\
\hline
\end{tabular}

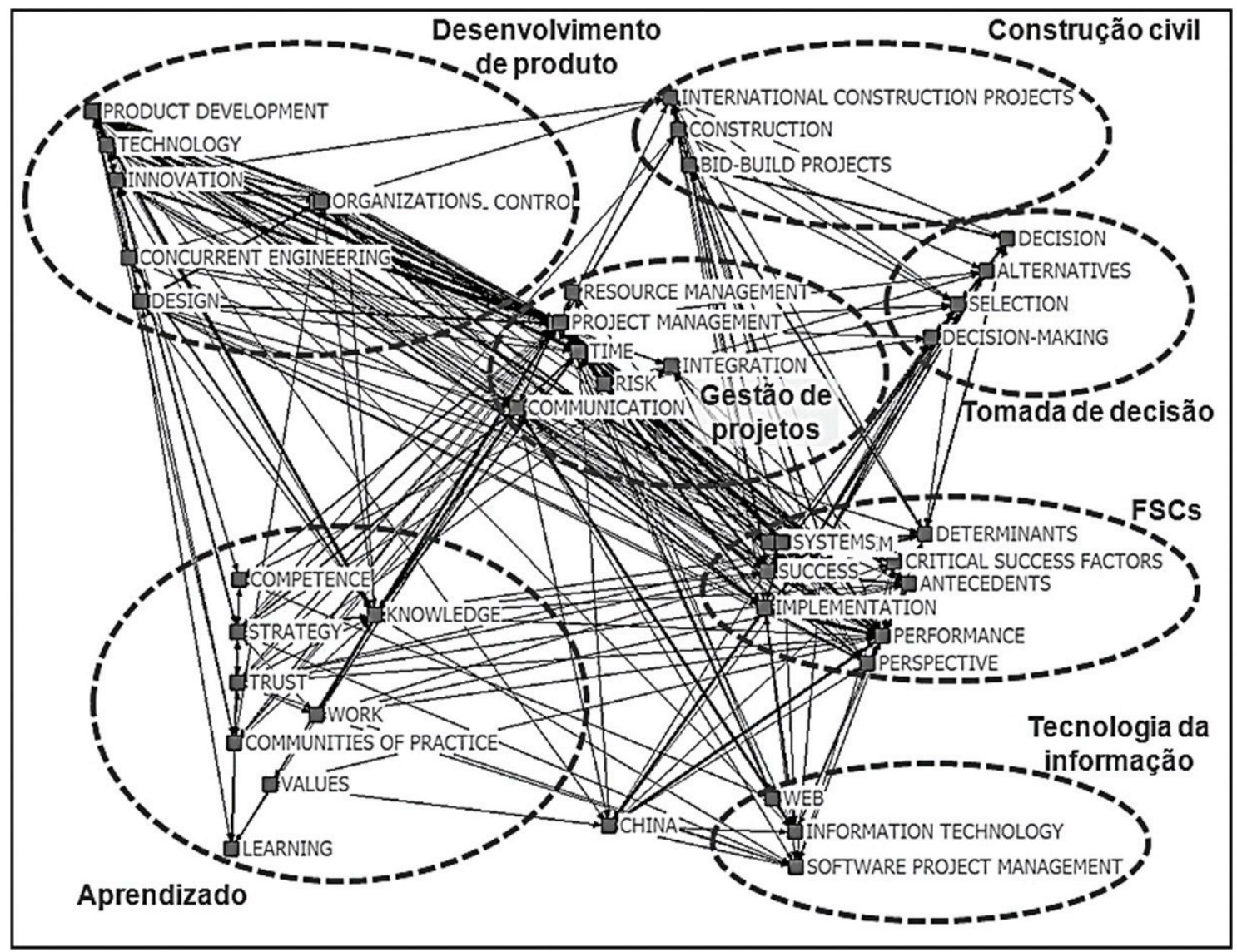

Figura 7. Rede de coocorrência de palavras-chave. Nota: Os quadrados representam as palavras-chave dos artigos da amostra que foram citados conjuntamente pelo menos duas vezes. A espessura das linhas representa a intensidade dos vínculos entre o par de palavras-chave. 
analisar as palavras-chave apenas dos artigos que possuíssem mais do que duas citações na data de extração dos dados e de acordo com a base de dados ISI.

Os resultados obtidos na rede de coocorrência de palavras-chave sugerem sete agrupamentos distintos:

- Núcleo de desenvolvimento do produto: engloba expressões relacionadas com os processos de engenharia concorrente e faz referência à inovação e tecnologia empregadas nos processos correlatos.

- Núcleo de aprendizado: apresenta um relacionamento de palavras envolvidas com a gestão do conhecimento em projetos e elementos que afetam o processo de aprendizado e compartilhamento de conhecimento.

- Núcleo de gerenciamento de projetos: gerado a partir do relacionamento de termos que remetem às áreas de conhecimento em gestão de projetos.

- Núcleo de FCS: envolve a proposta de modelos e sistemas para correta administração dos FCSs no ciclo de vida do projeto.

- Núcleo de tomada de decisão: relaciona termos inerentes ao processo decisório, tais como seleção e alternativas.

- Núcleo de TI: vertente ligada aos projetos de desenvolvimento de software e projetos de TI em geral.

- Núcleo de construção civil: abrange termos associados a obras e processos de projeto de engenharia civil.

Os resultados dos cálculos de centralidade e intermediação dos nós da rede de coocorrência de palavras-chave são mostrados nos Quadros 5 e 6, respectivamente. Por serem obtidos de forma automática, os resultados desses cálculos, muitas vezes, apresentam palavras de uso genérico de forma isolada, tais como "Management" e "Model". Dado que o conceito de palavra-chave é o de descritor, torna-se necessário desconsiderar tais termos em análises bibliométricas. Considerando-se, portanto, apenas as palavras-chave com função descritiva, os resultados dos dois cálculos evidenciaram um conjunto de palavras-chave similar, compostos pelos seguintes termos: "Project management", "product development", "innovation", "communication" e "knowledge".

\section{Discussão dos resultados}

\subsection{Panorama geral das publicações}

A análise inicial e descritiva das publicações da amostra evidenciou um interesse aparentemente cíclico da comunidade científica com a temática, refletindo a ausência de autores com grande volume de publicações. Considerando especificamente os anos com picos em volume de publicações, a análise dos artigos publicados em 2000, 2006 e 2010 demonstra, de forma geral, que a temática ao longo dos anos vem se tornando cada vez mais multidisciplinar, mas sempre objetivando, principalmente, o sucesso dos projetos. Com relação à distribuição das publicações por país de origem, percebe-se um destaque significativo dos Estados Unidos, embora, nos últimos anos, também seja observado um crescimento do número de publicações originárias de países como a Finlândia e a China. Um ponto comum abordado pelas publicações

Quadro 5. Resultados de centralidade para as palavras-chave da rede de coocorrência. Nota: Foram consideradas apenas as quinze palavras-chave com os maiores graus de centralidade.

\begin{tabular}{|l|c|c|}
\hline \multicolumn{1}{|c|}{ Palavra-chave } & Grau de centralidade & Grau de centralidade normalizado \\
\hline MANAGEMENT & 60,000 & 19,608 \\
\hline MODEL & 48,000 & 15,686 \\
\hline PERFORMANCE & 44,000 & 14,379 \\
\hline PROJECT MANAGEMENT & 43,000 & 14,052 \\
\hline PRODUCT DEVELOPMENT & 35,000 & 11,438 \\
\hline COMMUNICATION & 33,000 & 10,784 \\
\hline KNOWLEDGE & 33,000 & 10,784 \\
\hline IMPLEMENTATION & 30,000 & 9,804 \\
\hline SUCCESS & 29,000 & 9,477 \\
\hline INNOVATION & 25,000 & 8,170 \\
\hline SYSTEMS & 25,000 & 8,170 \\
\hline TIME & 23,000 & 7,516 \\
\hline STRATEGY & 17,000 & 5,556 \\
\hline DESIGN & 17,000 & 5,556 \\
\hline PERSPECTIVE & 16,000 & 5,229 \\
\hline
\end{tabular}


Quadro 6. Grau de intermediação para as palavras-chave da rede de coocorrência. Nota: Foram consideradas apenas as quinze palavras-chave com os maiores graus de intermediação.

\begin{tabular}{|l|c|c|}
\hline \multicolumn{1}{|c|}{ Palavra-chave } & Grau de intermediação & Grau de intermediação normalizado \\
\hline MANAGEMENT & 294,869 & 23,127 \\
\hline MODEL & 153,013 & 12,001 \\
\hline PROJECT MANAGEMENT & 121,542 & 9,533 \\
\hline PERFORMANCE & 76,367 & 5,990 \\
\hline SYSTEMS & 60,527 & 4,747 \\
\hline SUCCESS & 45,114 & 3,538 \\
\hline COMMUNICATION & 39,538 & 3,101 \\
\hline INNOVATION & 33,956 & 2,663 \\
\hline KNOWLEDGE & 33,498 & 2,627 \\
\hline PRODUCT DEVELOPMENT & 26,365 & 2,068 \\
\hline SELECTION & 18,870 & 1,480 \\
\hline TRUST & 17,469 & 1,370 \\
\hline STRATEGY & 17,412 & 1,366 \\
\hline TIME & 14,465 & 1,135 \\
\hline PERSPECTIVE & 13,134 & 1,030 \\
\hline
\end{tabular}

desses últimos países é a investigação dos desafios da gestão de projetos internacionais relacionados com as próprias particularidades culturais e comportamentais inerentes às sociedades desses países.

Também foi possível verificar que o tema gestão de projetos internacionais apresenta grande importância para as áreas de atividade econômica relacionadas com a construção civil, uma vez que um periódico desse setor encabeça a lista de revistas com maior volume de artigos publicados da amostra. Conforme Gunhan e Arditi (2005), a gestão eficiente do projeto internacional é uma das principais forças competitivas na indústria de construção civil internacional e a condução de projetos internacionais permite às empresas desse setor sobreviverem e crescerem ao mesmo tempo que competem com outras empresas que as ameaçam tanto nos mercados internacionais como no doméstico.

Verificou-se também que as publicações mais influentes da área estão relacionadas com o estudo da utilização de equipes virtuais ou globais em projetos de desenvolvimento de produtos ou projetos de $\mathrm{P} \& \mathrm{D}$ de novas tecnologias, sugerindo maior repercussão do estudo da gestão internacional de projetos em tais áreas de negócio. Analisando a aplicabilidade do desenvolvimento de projetos internacionais na área de P\&D, Boutellier et al. (1998) citam que a globalização de atividades de pesquisa e desenvolvimento representa um dos principais tópicos da área de gerenciamento e as principais forças impulsionando a internacionalização do $\mathrm{P} \& \mathrm{D}$ são a necessidade de processo de desenvolvimento orientado ao mercado e a possibilidade de acesso aos melhores recursos humanos ao redor do globo. Nesse contexto, equipes dispersas conduzindo grandes projetos através de fronteiras nacionais estão sendo crescentemente utilizadas a fim de explorar as potenciais vantagens da internacionalização do processo de P\&D (BOUTELLIER et al., 1998; McDONOUGH et al., 2001).

\subsection{Pilares teóricos}

A análise da rede de relacionamento entre os artigos da amostra e suas referências não evidenciou nenhuma concentração de destaque, entretanto, pôde-se observar uma relativa concentração de trabalhos em quatro referências específicas: Eisenhardt (1989), Hofstede (1980), Gersick (1988) e Wheelwright e Clark (1992).

Embora a utilização do método de bola de neve tenha resultado na inclusão dos trabalhos de Eisenhardt (1989) e Wheelwright e Clark (1992) dentre as referências citadas da amostra de publicações, esses estudos não versam diretamente sobre o tema de gestão de projetos internacionais. Entretanto, a elaboração da rede de relacionamento entre os artigos da amostra e suas referências mostra que eles foram importantes referências para a construção das pesquisas. O trabalho de Eisenhardt (1989) foi utilizado por pelo menos três artigos como suporte metodológico para as pesquisas conduzidas no formato de estudo de caso. Já os artigos da amostra que referenciam o trabalho de Wheelwright e Clark (1992) o utilizam como suporte teórico tanto para o estudo do processo de desenvolvimento de produto em ambiente internacional (LINDKVIST; SÖDERLUND; TELL, 1998; SÖDERLUND, 2002), assim como também para a investigação de métodos de promoção do aprendizado em projetos globais, considerando a 
existência de centros locais de especialização dispersos pelo globo (SMEDS; OLIVARI; CORSO, 2001).

O trabalho de Hofstede (1980) representa um estudo transcultural procurando avaliar valores de funcionários de uma empresa multinacional e discute a existência de quatro dimensões básicas que influenciam os valores humanos, denominadas de: Distância Hierárquica; Individualismo versus Coletivismo; Masculinidade versus Feminilidade; e Evitação de Incerteza. Os artigos da amostra selecionada que referenciam o trabalho de Hofstede (1980) utilizam essas dimensões para justificar os diferentes padrões de desempenho e aprendizado de equipes de projeto, observados na condução de estudos comparativos internacionais (SOUDER; JENSSEN, 1999; HAYNE; POLLARD, 2000; SMEDS; OLIVARI; CORSO, 2001).

Já o trabalho de Gersick (1988) aborda a organização do trabalho e trata-se de um estudo que compreende a análise do ciclo de vida de várias equipes de trabalho. Sua pesquisa foca, principalmente, o comportamento do progresso dos grupos de trabalho com relação ao andamento das atividades requeridas pelos projetos. Os artigos da amostra que citam o trabalho de Gersick (1988) aplicam métodos de controle de progresso do projeto apresentados nessa referência na administração de projetos de desenvolvimento de produto e de construção civil compostos por equipes virtuais ou dispersas geograficamente (LINDKVIST; SÖDERLUND; TELL, 1998; SÖDERLUND, 2002; CHINOWSKY; ROJAS, 2003).

O aparecimento dos trabalhos de Hofstede (1980) e Gersick (1988) como sendo umas das referências mais citadas na amostra sugere que as teorias desenvolvidas em relação às diferenças comportamentais e culturais dos indivíduos são um dos pilares teóricos a serem considerados em estudos abordando a gestão de projetos internacionais.

A análise da rede de cocitação das referências dos artigos da amostra evidenciou agrupamentos relacionados com temáticas diversas: FCS; diferenças culturais entre sociedades; métodos qualitativos de pesquisa; gestão de projetos de grande porte; gestão de organizações temporárias; e estudos comportamentais humanos. A seguir é feita uma breve discussão desses trabalhos do ponto de vista de gestão de projetos internacionais.

Os trabalhos de Fortune e Diana (2006) e Belassi e Tukel (1996) abordam o tema de fatores críticos de sucesso em projetos a partir de uma crítica às infindáveis listas de fatores relacionadas na literatura, as quais, muitas vezes, por serem específicas acabam não auxiliando a gestão de projetos na prática. Em virtude desse cenário, ambos os trabalhos propõem modelos de classificação e organização dos FCSs objetivando melhor utilização prática e obtenção de benefícios reais a partir desses fatores. A identificação desse agrupamento demonstra que, apesar de o foco da amostra e o objeto de estudo abordar a gestão de projetos internacionais, sempre há, na literatura, independentemente da perspectiva de análise, uma preocupação com o resultado final representado pelo sucesso do projeto.

Os trabalhos de Hofstede $(1980,2001)$ apresentam uma análise de diferenças culturais e de pensamento entre nações e organizações que muitas vezes estão na origem de problemas sociais complexos. Chevrier (2003) e Orr e Scott (2008), partindo dos mesmos princípios, abordam os problemas culturais existentes em projetos internacionais e como a negligência de tais diferenças na organização da equipe de projeto pode levar a falhas e ao aumento dos custos do projeto. O aparecimento de tal agrupamento é plausível em virtude de tratar-se de um cenário estritamente relacionado com a gestão de projetos internacionais, em que os gerentes de projeto precisam lidar com diferenças culturais organizacionais e pessoais. Esse resultado corrobora a importância da questão da diversidade cultural no gerenciamento de projetos internacionais, evidência que também esteve presente na análise das referências mais citadas da amostra.

Os trabalhos de Staw e Ross (1987) e Pfeffer e Salancik (1978) analisam diversas facetas do comportamento humano em organizações e Söderlund (2004) apresenta perspectivas futuras da gestão de projetos enfatizando a necessidade de entendimento do comportamento de organizações orientadas a projeto. Com a identificação desse agrupamento, esperava-se encontrar uma ligação estreita com o agrupamento que aborda as diferenças culturais, uma vez que os aspectos comportamentais e culturais geralmente estão inter-relacionados. Entretanto, a partir da rede obtida não foi possível identificar uma ligação destacável. Portanto, sugere-se que a necessidade identificada nesse agrupamento esteja relacionada com o fato de as organizações que gerenciam projetos que atravessam fronteiras internacionais geralmente encontrarem grandes dificuldades em implementar seu planejamento e o viés comportamental humano pode ser um dos pilares contribuintes para tal cenário.

O texto de Turner (1999) trata-se de um handbook de gestão de projetos orientado à entrega de deliverables organizacionais, enquanto o trabalho de Engwall (2003) apresenta um panorama evolutivo das práticas de gestão de projetos ao longo do tempo. Em seguida, o trabalho de Flyvbjerg, Bruzelius e Rothengatter (2003) discute as práticas de gestão de projetos de grande porte, necessidade justificada pelos elevados riscos de descumprimento de custo e prazo em tais projetos. A identificação de tal agrupamento enfatiza a internacionalização de grandes projetos de infraestrutura possibilitada pelo fenômeno da globalização, ao mesmo tempo em que destaca a necessidade de práticas diferenciadas para gerir tais projetos. 
Os trabalhos de Gersick (1988), Packendorff (1995) e Lundin e Södeholm (1995) propõem teorias para gestão de projetos em organizações temporárias ou ágeis e Wheelwright e Clark (1992) e Eisenhardt e Tabrizi (1995) apresentam a mesma abordagem no contexto do ambiente de desenvolvimento de produtos. Notadamente a identificação desse agrupamento relaciona-se com a prática cada vez mais comum de as organizações conduzirem projetos de desenvolvimento de produtos constituídos por equipes globais no intuito de obter as vantagens propiciadas tanto pela inovação como pelo conhecimento de diferentes mercados.

Os trabalhos de Eisenhardt (1989) e Miles e Huberman (1984), embora não representem pilares teóricos da temática de gestão de projetos internacionais, discutem, respectivamente, o processo de construção teórica a partir da pesquisa baseada em estudo de caso e as vantagens da abordagem de pesquisa qualitativa. Constituem, portanto, um agrupamento que foi utilizado como suporte metodológico para as pesquisas qualitativas ou desenvolvidas no formato de estudo de caso.

Os trabalhos de Allen (1977), Shenhar e Dvir (1996), Konchar e Sanvido (1998) e Ginevicius, Podvezkoa e Bruzgeb (2008), embora representem estudos importantes para a composição da base teórica das publicações da amostra, não foram agrupados em um primeiro momento por destoarem do foco principal dos agrupamentos identificados ou localizarem-se na interface de dois agrupamentos. $\mathrm{O}$ trabalho de Allen (1977) aborda, em profundidade, a importância da informação e comunicação para o bom desempenho de organizações de P\&D. Já Shenhar e Dvir (1996) apresentam uma teoria para tipologia bidimensional de projetos e destacam a necessidade de uma abordagem contingencial para a gestão de projetos. Objetivando investigar o sucesso de projetos de construção civil, Konchar e Sanvido (1998) comparam empiricamente os métodos utilizados para entrega de projetos no setor de construção civil dos Estados Unidos utilizando informações de custo, prazo e qualidade de desempenho de projetos. Ginevicius, Podvezkoa e Bruzgeb (2008) investigam a influência dos subsídios estatais no sucesso de projetos tendo como foco projetos desenvolvidos na comunidade europeia.

Os cálculos de centralidade e intermediação das publicações constituintes da rede de cocitação novamente evidenciaram os trabalhos de Eisenhardt (1989) e Hofstede (1980, 2001), respectivamente. Esses resultados sugerem que grande parte da literatura disponível envolvendo o tema de gerenciamento de projetos internacionais apoia-se em pesquisas de caráter qualitativo e cujas bases teóricas remetem a investigações de diferenças culturais e comportamentais entre indivíduos.

\subsection{Temáticas da área}

Os resultados obtidos na análise da rede de coocorrência das palavras-chave demonstram as principais vertentes dos estudos disponíveis no campo de gestão de projetos internacionais.

Como já era de certa forma esperado, há uma concentração de publicações abordando a gestão de projetos internacionais nas áreas de desenvolvimento de novos produtos, TI e construção civil. Notadamente essas são indústrias que tradicionalmente desenvolvem projetos que ultrapassam as fronteiras nacionais e compostos por equipes estão distribuídas por todo o globo. O processo de internacionalização da indústria da construção civil alavanca e depende fortemente da utilização de projetos internacionais. Segundo Gunhan e Arditi (2005), embora o processo de internacionalização da construção civil não seja um fenômeno recente, a globalização proporciona novas oportunidades para as empresas da construção civil. Ao mesmo tempo que países em desenvolvimento necessitam de nova infraestrutura e são receptivos a empreiteiras de países industrializados, a redução das barreiras internacionais permite às empreiteiras conduzirem projetos também em outros países desenvolvidos. Na área de TI, Kirsch (2004) cita que um número cada vez maior de empresas está desenvolvendo, por meio de projetos internacionais, sistemas de informação (SI) comuns que são implementados em escala global a fim de suportar as iniciativas estratégicas de internacionalização das organizações. Por outro lado, as organizações também estão concluindo que os conhecimentos necessários para o desenvolvimento de novos produtos podem estar dispersos ao redor do mundo e projetos constituídos por equipes globais ou transnacionais podem ser utilizados com o objetivo de empregar o conhecimento globalmente disperso sem a necessidade de fisicamente alocar os membros das equipes (McDONOUGH et al., 2001).

Outro resultado esperado obtido na análise de coocorrência das palavras-chave foram os agrupamentos de publicações tratando da temática do gerenciamento das áreas de conhecimento em gestão de projetos e da temática de FCS. Embora o foco da busca inicial dos artigos da amostra tenha sido a gestão de projetos internacionais, esse tema consiste na verdade em uma especificação da disciplina de gestão de projetos. Portanto, considera-se natural o aparecimento de agrupamentos relacionados com vertentes que abordem temas tradicionais do gerenciamento de projetos. Destaque particular é conferido à área de gestão da comunicação em projetos internacionais. De forma geral, as pesquisas demonstram que enquanto a proximidade física dos membros das equipes de projeto pode reforçar a similaridade social, valores compartilhados e expectativas, o distanciamento geográfico entre os 
membros da equipe de projeto pode negativamente afetar o grau de confiança e cooperação entre si mesmos, levando a grandes restrições de comunicação (BOUTELLIER et al., 1998; McDONOUGH et al., 2001; SAPSED; SALTER, 2004).

Dois resultados inesperados foram encontrados na análise da rede de coocorrência de palavraschave. O primeiro foi o surgimento de um núcleo relacionado com a temática do aprendizado em gestão de projetos. De acordo com Gassmann e von Zedtwitz (1998), fenômenos benéficos de transferência de conhecimento podem ocorrer quando pessoas de diferentes localidades tornam-se parte da mesma equipe de projeto, como geralmente ocorre no caso de projetos internacionais. Entretanto, segundo Sapsed e Salter (2004), grupos locais de trabalho tendem a apresentar melhor desempenho e compartilham conhecimento de forma mais eficiente do que grupos dispersos. A justificativa associada é a de que, no contexto local, a proximidade geográfica entre os indivíduos permite a interação face a face de forma intensa e contínua, sendo benéfica para a comunicação organizacional.

O segundo resultado inesperado foi a identificação de um núcleo relacionado com o processo de tomada de decisão. Como outros estudos já sugeriram, a capacidade de tomada de decisão é uma das características mais valorizadas em um profissional de gestão de projetos (PATAH; CARVALHO, 2002; STARKWEATHER; STEVENSON, 2011). O aparecimento de tal núcleo na análise da amostra de artigos em gestão de projetos internacionais pode sugerir que a importância de tal característica seja enfatizada no contexto de projetos que expandem fronteiras nacionais. Os projetos internacionais frequentemente envolvem a utilização de equipes de projeto compostas por grupos multiculturais, os quais, de forma geral, falham em perceber seu potencial para um processo de tomada de decisão complexo (McDONOUGH et al., 2001). Embora equipes multiculturais, em comparação com times de menor diversidade cultural, possuam maior nível de criatividade e tendam a desenvolver soluções melhores e em maior número para um determinado problema, os desafios muitas vezes encontrados para a resolução de conflitos, criação de coesão e confiança entre os membros podem afetar negativamente o desempenho e qualidade da decisão.

Os cálculos de centralidade e intermediação das palavras-chave constituintes da rede de cocitação evidenciaram os seguintes termos: "project managment"; "product development"; "innovation"; "communication"; e "knowledge". Considerando que a palavra-chave "Project Management" foi utilizada como critério de busca para composição da amostra de artigos, torna-se desnecessário considerá-la para análise da relevância dos tópicos identificados na rede de coocorrência de palavras-chave. Dado que a característica de alta centralidade de um ator em uma rede social, representado por graus de centralidade e intermediação elevados, reflete uma maior importância do ator central em relação aos demais atores da rede, observa-se que o núcleo temático de desenvolvimento de produto, associado às palavras-chave "product development" e "innovation"; a temática da gestão da comunicação, associada à palavra-chave "communication"; e temática de gestão do conhecimento, associada à palavra-chave "knowledge" figuram entre as principais discussões e investigações dos estudos publicados até o momento no campo da gestão de projetos internacionais. Trata-se de um resultado alinhado com a análise dos pilares teóricos da literatura de gestão de projetos internacionais, a qual destacou a importância de teorias relacionadas com aspectos culturais e comportamentais dos indivíduos. A coerência se justifica pelo fato de que a diversidade cultural e comportamental frequentemente presente em equipes de projeto internacionais adicionam barreiras à comunicação eficiente e, por conseguinte, afetam um aspecto mais complexo da comunicação: a transferência de conhecimento entre membros de tais equipes.

A análise de literatura conduzida, portanto, sugere que um elemento-chave para a condução bem-sucedida de projetos internacionais reside no entendimento das diferentes bases culturais e comportamentais de todos os envolvidos no projeto. O gerenciamento adequado de tais elementos permite o estabelecimento apropriado de processos fundamentais para o funcionamento do projeto internacional, tais como a comunicação, transferência de conhecimento e aprendizado entres os membros do projeto e tomada de decisão.

\section{Conclusões}

O presente trabalho objetivou analisar a literatura sobre o tema de gestão de projetos internacionais, ao mesmo tempo buscando identificar os principais desafios e características do gerenciamento deste tipo de projeto. As análises descritivas das publicações foram utilizadas para traçar um panorama geral das publicações e as análises de redes sociais auxiliaram na identificação tanto das bases teóricas, como também das principais temáticas abordadas pelos artigos dessa área de pesquisa. Os resultados sugerem que os temas abordados de forma mais frequente até o momento estão associados à utilização dos projetos internacionais no processo global de $\mathrm{P} \& \mathrm{D}$ e de desenvolvimento de produtos e à gestão da comunicação e do conhecimento em projetos internacionais. Ademais, os resultados também sugerem que grande parte das pesquisas desenvolvidas até o momento apoia-se em bases teóricas relacionadas com diferenças culturais e comportamentais entre indivíduos. 
A análise da literatura conduzida sugere que um dos principais desafios à gestão de projetos internacionais está associado a dificuldades de integração adequada do projeto em si e suas equipes dispersas, as quais, muitas vezes, são originárias da grande diversidade cultural e comportamental de todos os envolvidos no projeto. De acordo com Kruglianskas e Tamhain (2000), os projetos internacionais necessitam ser integrados por meio de diferentes regiões geográficas, diferentes processos de negócios, estilos gerenciais, sistemas de suporte operacional e culturas organizacionais; contexto que, como sugerido neste estudo, pode resultar em problemas de comunicação, compartilhamento de conhecimento e tomada de decisão e, por conseguinte, prejudicar o gerenciamento efetivo e o sucesso dos projetos internacionais.

Embora a análise de redes sociais não tenha explicitado, outros desafios foram reportados na literatura pesquisada e que também, muitas vezes, estão relacionados com as dificuldades de integração do projeto internacional. Um deles está relacionado com a possibilidade do projeto possuir um conjunto maior e mais diversificado de patrocinadores, fato que pode dificultar a obtenção de satisfação final com o projeto. Os projetos internacionais necessitam atender aos requerimentos de um conjunto diverso de patrocinadores com diferentes necessidades de negócio, prioridades e objetivos e, nesse contexto, questões políticas, motivação e conflitos originários das interações entre os patrocinadores podem desencaminhar projetos internacionais. Outra questão refere-se à competência do gerente de projeto em lidar com os desafios técnicos e administrativos advindos do cenário internacional mais complexo. Os projetos internacionais são sensíveis a eventos mundiais e, por esse motivo, estão sujeitos a riscos políticos, financeiros, culturais e legais mais numerosos e menos previsíveis. Nesse caso, gerentes de projeto envolvidos em projetos que ultrapassem as fronteiras nacionais necessitam, além de conhecimento de regulamentos e padrões internacionais, cuidados adicionais na negociação de fatores econômicos devido à inflação, flutuações de taxas de câmbio e complexidades adicionais com impostos. Estudos relacionados com esses desafios apareceram de forma menos frequente na amostra pesquisada e podem representar oportunidades futuras de pesquisa.

É importante ressaltar que os resultados desta pesquisa não podem ser totalmente generalizados, pois se baseiam em uma amostra de publicações contidas na base de dados do ISI Web of Knowledge (Web of Science). As redes obtidas, porém, permitiram analisar não só os 75 trabalhos da amostra, mas também todas as referências utilizadas por esses trabalhos, resgatando livros e artigos que poderiam estar em outras bases de dados. Portanto, tanto o método selecionado como os dados obtidos a partir dessa base mostraram-se apropriados para atingir o objetivo do trabalho, desenvolvimento dos resultados, análises e discussões.

Do ponto de vista prático espera-se que os resultados deste trabalho, ao explorar os elementos associados à gestão de projetos internacionais, possam auxiliar as organizações e gerentes de projetos atuando em um contexto global com um entendimento inicial dos desafios e complexidades que precisam ser devidamente gerenciados para o sucesso de suas jornadas internacionais.

\section{Agradecimentos}

Os autores agradecem aos avaliadores o esmerado trabalho de revisão do texto original, cujos comentários e recomendações muito contribuíram para a versão final deste artigo.

\section{Referências}

AALTONEN, K. Project stakeholder analysis as an environmental interpretation process. International Journal of Project Management, v. 29, n. 2, p. 165-183, 2011. http://dx.doi.org/10.1016/j. ijproman.2010.02.001

ALLEN, T. J. Managing the flow of technology: technology transfer and the dissemination of technological information within the R\&D organization. Cambridge: MIT Press, 1977. 329 p.

BELASSI, W.; TUKEL, O. I. A new framework for determining critical success/failure factors in projects. International Journal of Project Management, v. 14, n. 3 , p. 141-151, 1996. http://dx.doi. org/10.1016/0263-7863(95)00064-X

BODEA, C. et al. Modeling project management competencies using an ontological approach. Computation and Economic Cybernetics Studies and Research, v. 44, n. 2, p. 33-47, 2010.

BORGATTI, S.; EVERETT, M.; FREEMAN, L. Ucinet for Windows: software for social network analysis. Boston: Analytic Technologies, 2002.

BOUTELLIER, R. et al. Management of dispersed product development teams: the role of information technologies. R\&D Management, v. 28, n. 1, p. 13-25, 1998.

CHEVRIER, S. Cross-cultural management in multinational project groups. Journal of World Business, v. 38, n. 2, p. 141-149, 2003. http://dx.doi.org/10.1016/ S1090-9516(03)00007-5

CHIESA, V. Global R\&D project management and organization: a taxonomy. Journal of Product Innovation Management, v. 17, n. 5, p. 341-359, 2000.

CHINOWSKY, P. S.; ROJAS, E. M. Virtual teams: guide to successful implementation. Journal of Management in Engineering, v. 19, n. 3, p. 98-106, 2003.

EISENHARDT, K. M. Building theories from case study research. Academy of Management Review, v. 14, n. 4, p. 532-550, 1989.

EISENHARDT, K. M.; TABRIZI, B. N. Accelerating adaptive processes: product innovation in the 
global computer industry. Administrative Science Quarterly, v. 40, n. 1, p. 84-110, 1995. http://dx.doi. org/10.2307/2393701

ENGWALL, M. No project is an island: linking projects to history and context. Research Policy, v. 32, n. 5, p. 789-808, 2003. http://dx.doi.org/10.1016/ S0048-7333(02)00088-4

ETHIRAJ, S. K. et al. Where do capabilities come from and how do they matter? Strategic Management Journal, v. 26, n. 1, p. 25-45, 2005.

FLEURY, A.; FLEURY, M. T. Brazilian multinationals: competences for internationalization. Cambridge: Cambridge University Press, 2011. 460 p. http://dx.doi. org/10.1017/CBO9780511933844

FLYVBJERG, B.; BRUZELIUS, N.; ROTHENGATTER, W. Megaprojects and risk: an anatomy of ambition. Cambridge: Cambridge University Press, 2003.

FORTUNE, J.; DIANA, W. Framing of project critical success factors by a systems model. International Journal of Project Management, v. 24, n. 1, p. 53-65, 2006. http:// dx.doi.org/10.1016/j.ijproman.2005.07.004

GASSMANN, O.; VON ZEDTWITZ, M. Organization of industrial R\&D on a global scale. R\&D Management, v. 28, n. 3, p. 147-161, 1998.

GERSICK, C. J. G. Time and transition in work teams: toward a new model of group development. The Academy of Management Journal, v. 31, n. 1, p. 9-41, 1988. http://dx.doi.org/10.2307/256496

GINEVICIUS, R.; PODVEZKOA, V.; BRUZGEB, S. Evaluating the effect of state aid to business by multicriteria methods. Journal of Business Economics and Management, v. 9, n. 3, p. 167-180, 2008. http:// dx.doi.org/10.3846/1611-1699.2008.9.167-180

GUMPENBERGER, M. W. C.; GORRAIZ, J. Bibliometric practices and activities at the University of Vienna. Library Management, v. 33, n. 3, p. 174-183, 2012. http://dx.doi.org/10.1108/01435121211217199

GUNHAN, S.; ARDITI, D. Factors affecting international construction. Journal of Construction Engineering and Management, v. 131, n. 3, p. 273-282, 2005.

HAYNE, S. C.; POLLARD, C. E. A comparative analysis of critical issues facing Canadian information systems personnel: a national and global perspective. Information \& Management, v. 38, n. 2, p. 73-86, 2000.

HOFSTEDE, G. Culture's consequences: international differences in work- related values. Beverly Hills: Sage, 1980 .

HOFSTEDE, G. Culture's consequences: international differences in work-related values. Thousand Oakes: Sage, 2001

IBBS, C. W. et al. Project delivery systems and project change: qualitative analysis. Journal of Construction Engineering and Management, v. 129, n. 4, p. 382-387, 2003. http://dx.doi.org/10.1061/ (ASCE)0733-9364(2003)129:4(382)

JOURNAL CITATION REPORTS - JCR. New York: Thomson Reuters. Disponível em: <http://admin-apps. webofknowledge.com/JCR/JCR?PointOfEntry=Home\& $\mathrm{SID}=2 \mathrm{BH} 5 \mathrm{CFJG6GFKo29ebJ}>$. Acesso em: mar. 2013.

JUNG, J. Y.; WANG, Y. H. Relationship between total's quality management (TQM) and continuous improvement of international project management (CIIPM). Technovation, v. 26, n. 5-6, p. 716-722, 2006.

KIRSCH, L. I. Deploying common systems globally: the dynamics of control. Information Systems Research, v. 15, n. 4, p. 374-395, 2004.

KONCHAR, M.; SANVIDO, V. Assessing cost uncertainty: lessons from environmental restoration projects. Journal of Construction Engineering and Management, v. 124, n. 6, p. 435-445, 1998.

KRUGLIANSKAS, I.; THAMHAIN, H. J. Managing technology-based projects in multinational environments. IEEE Transactions on Engineering Management, v. 47, n. 1, p. 55-64, 2000.

LINDKVIST, L.; SÖDERLUND, J.; TELL, F. Managing product development projects: on the significance of fountains and deadlines. Organization Studies, v. 19, n. 6, p. 931-951, 1998.

LING, F. Y. Y. et al. Models for predicting project performance in China using project management practices adopted by foreign AEC firms. Journal of Construction Engineering and Management, v. 134, n. 12, p. 983-990, 2008.

LING, F. Y. Y. et al. Key project management practices affecting Singaporean firms' project performance in China. International Journal of Project Management, v. 27, n. 1, p. 59-71, 2009.

LOPES, A. P. V. B. V.; CARVALHO, M. M. Evolução da literatura de inovação em relações de cooperação: um estudo bibliométrico num período de vinte anos. Gestão \& Produção, v. 19, n. 1, p. 203-217, 2012. http://dx.doi. org/10.1590/S0104-530X2012000100014

LUNDIN, R. A.; SÖDEHOLM, A. A theory of the temporary organization. Scandinavian Journal of Management, v. 11, n. 4, p. 437-455, 1995. http:// dx.doi.org/10.1016/0956-5221(95)00036-U

McDONOUGH, E. F.; KAHN, K. B.; BARCZAK, G. An investigation of the use of global, virtual, and collocated new product development teams. Journal of Product Innovation Management, v. 18, p. 110-120, 2001.

MILES, M. B.; HUBERMAN, A. M. Qualitative data analysis: a sourcebook of new methods. California: Sage Publications, 1984.

MONTEALEGRE, R.; KEIL, M. De-escalating information technology projects: lessons from the Denver international airport. Mis Quarterly, v. 24, n. 3, p. 417-447, 2000.

MULLER, R.; TURNER, J. R. Attitudes and leadership competences for project success. Baltic Journal of Management, v. 5, n. 3, p. 307-329, 2010.

ORR, J.; SCOTT, W. R. Institutional exceptions on global projects: a process model. Journal of International Business Studies, v. 39, n. 4, p. 562-588, 2008.

PACKENDORFF, J. Inquiring into the temporary organization: new directions for project management research. Scandinavian Journal of Management, v. 1, n. 4, p. 319-333, 1995. http://dx.doi. org/10.1016/0956-5221(95)00018-Q

PATAH, L. A.; CARVALHO, M. M. Estruturas de gerenciamento de projetos e competências em equipes de projetos. In: ENCONTRO NACIONAL DE ENGENHARIA DE PRODUÇÃO, 22., 2002, Curitiba. Anais... 
PFEFFER, J.; SALANCIK, G. R. A social information processing approach to job attitudes and task design. Administrative Science Quarterly, v. 23, n. 2, p. 224-253, 1978.

SAPSED, J.; SALTER, A. Postcards from the edge: local communities, global programs and boundary objects. Organization Studies, v. 25, n. 9, p. 1515-1534, 2004.

SCHILDT, H. A. Sitkis: software for bibliometric data management and analysis v6.1. Helsinki: Institute of Strategy and International Business, 2002.

SHENHAR, A. J.; DVIR, D. Toward a typological theory of project management. Research Policy, v. 25, n. 4 , p. $607-632,1996$. http://dx.doi. org/10.1016/0048-7333(95)00877-2

SMALL, H. Paradigms, citations, and maps of science: a personal history. Journal of the American Society for Information Science and Technology, v. 54, n. 5, p. 394-399, 2003.

SMEDS, R.; OLIVARI, P.; CORSO, M. Continuous learning in global product development: a cross-cultural comparison. International Journal of Technology Management, v. 22, n. 4, p. 373-392, 2001.

SÖDERLUND, J. Managing the project management process. R\&D Management, v. 32, p. 419-430, 2002.

SÖDERLUND, J. Building theories of project management: past research, questions for the future. International Journal of Project Management, v. 22, n. 3, p. 183-191, 2004. http://dx.doi.org/10.1016/ S0263-7863(03)00070-X

SOTOMONTE, E. P. S.; SILVA, C. E. S. Equipes virtuais: uma análise bibliométrica. In: SIMPÓSIO DE ENGENHARIA DE PRODUÇÃO, 18., 2011, Bauru.

SOUDER, W. E.; JENSSEN, S. A. Management practices influencing new product success and failure in the United
States and Scandinavia: a cross-cultural comparative study. Journal of Product Innovation Management, v. 16, n. 2, p. 183-203, 1999.

STARKWEATHER, J. A.; STEVENSON, D. H. PMP® certification as a core competency: necessary but not sufficient. Project Management Journal, v. 42, n. 1, p. 31-41, 2011. http://dx.doi.org/10.1002/pmj.20174

STAW, B. M.; ROSS, J. Behavior in escalation situations: antecedents, prototypes, and solutions. Research in Organizational Behavior, v. 9, p. 39-78, 1987.

STEFFEY, R. W.; ANANTATMULA, V. S. International projects proposal analysis: risk assessment using radial maps. Project Management Journal, v. 42, n. 3, p. 62-74, 2011. http://dx.doi.org/10.1002/pmj.20237

SUN, J.; WANG, M. H.; HO, Y. S. A historical review and bibliometric analysis of research on estuary pollution. Marine Pollution Bulletin, v. 64, n. 1, p. 13-21, 2012. PMid:22119413. http://dx.doi.org/10.1016/j. marpolbul.2011.10.034

TURNER, J. R. The handbook of project based management: improving the processes for achieving strategic objectives. Maidenhead: McGraw-Hill, 1999.

WASSERMAN, S.; FAUST, K. Social network analysis: methods and applications. Cambridge: Cambridge University Press, 1994. http://dx.doi.org/10.1017/ CBO9780511815478

WHEELWRIGHT, S. C.; CLARK, K. B. Revolutionizing product development: quantum leaps in speed, efficiency, and quality. New York: The Free Press, 1992.

YAN, Y. H.; KUPHAL, T.; BODE, J. Application of multiagent systems in project management. International Journal of production economics, v. 68, n. 2, p. $185-197,2000$. 